\title{
Systemic Administration of miRNA Mimics by Liposomal Delivery System in Animal Model of Colorectal Carcinoma
}

\author{
J. MERHAUTOVÁ ${ }^{1,2}$, P. VYCHYTILOVÁ-FALTEJSKOVÁ ${ }^{1}$, R. DEMLOVÁ ${ }^{2}$, O. SLABÝ ${ }^{1}$ \\ ${ }^{1}$ Molecular Oncology II - Solid Cancer, CEITEC, Masaryk University, Brno, Czech Republic, \\ ${ }^{2}$ Department of Pharmacology, Faculty of Medicine, Masaryk University, Brno, Czech Republic
}

Received August 28, 2016

Accepted September 12, 2016

\begin{abstract}
Summary
MiRNAs are important regulators of gene expression and changes in their levels are linked with various pathological states, including solid tumors. MiR-215 has been identified as a tumor suppressor in colorectal cancer (CRC). Following our previous in vitro and in vivo experiments, the aim of this project was to study the possibility of increasing the levels of miR-215 in tumor cells by systemic administration of miRNA mimics in liposomal delivery system in vivo. By subcutaneous xenotransplantation of human cancer cells to NSG mice, CRC model was established. The treatment [miR-215 mimics in liposomes (20 and $40 \mu \mathrm{g} /$ mouse), control oligonucleotide in liposomes, or saline] was administered repeatedly by i.v. injection via tail-vein. Animals were sacrificed, tumor were dissected and measured by a caliper. Expression of miR-215 in tumors, lungs and liver was quantified by RT-PCR. There was no significant differences in tumor volume and miR-215 expression between all three treatment groups. Therefore, the decrease in tumor volume was not achieved. By comparing the levels of miR-215 in lungs, liver and tumors after the treatment, we suggest that the liposomes are accumulated in the lungs and do not concentrate sufficiently in the tumor site to exert significant tumor-suppressive effect.
\end{abstract}

\section{Key words}

Colorectal neoplasms • microRNAs • Liposomes • Mice

\section{Corresponding author}

O. Slabý, Molecular Oncology II - Solid Cancer, CEITEC, Masaryk University, Kamenice 5, 62500 Brno, Czech Republic. E-mail: ondrej.slaby@ceitec.muni.cz

\section{Introduction}

Colorectal carcinoma (CRC) represents the second most frequent cancer disease in men and women in the Czech Republic. For the last 10 years, the incidence of CRC is stable ranging around 80 cases per 100,000 persons a year and the mortality is slowly decreasing (Dušek et al. 2007, Ferlay et al. 2013). Nevertheless, a large proportion of patients is diagnosed with advanced or metastatic disease (stages III, IV). Clinical outcomes of therapy in metastatic stage are quite worse in comparison with early (I, II) stages and the pharmacotherapy is mostly palliative.

Treatment of advanced and metastatic CRC consists of chemotherapy regimens based on 5-fluorouracil (5-FU) and leucovorin combined with irinotecan, or oxaliplatin. 5-FU could be also replaced with capecitabine (Fínek et al. 2016). Cytostatics are nowadays frequently combined with targeted therapy. There are more target molecules: epidermal growth factor receptor (EGFR), vascular endothelial growth factor (VEGF), and tyrosine kinases associated with various receptors including VEGFR, PDGFR, FGFR, KIT, RET etc. The most frequently used targeted therapy agents are monoclonal antibodies against EGFR (cetuximab, panitumumab) and VEGF (bevacizumab). Anti-EGFR therapy is designated for patients with confirmed wildtype $R A S$ oncogene (KRAS, NRAS), as mutations in $R A S$ are associated with poor anti-EGFR therapy outcomes (Lin et al. 2011, Adelstein et al. 2011). Multikinase inhibitor regorafenib, and fusion protein ("soluble VEGF receptor") aflibercept are designated for patients with progression on standard therapy, or intolerance of it 
(Van Cutsem et al. 2016, Fínek et al. 2016).

Even in this more targeted and moderately personalized treatment settings, a group of patients does not have clinical benefit from the therapy, or their tumor gains secondary resistance. Besides finding new predictive biomarkers to distinguish more precisely patients with or without clinical benefit from the therapy in advance, there is a constant need to bring new therapeutics with new mechanisms of action into the clinical practice. MiRNA-based therapeutics, that emerged in the drug research and development with increasing knowledge about the roles of miRNAs in the cell and in the cancer cell specifically, could represent such new targeted substances and some of them are heading towards the clinical practice. Besides growing number of in vitro and in vivo studies that aim to discover potential therapeutic properties of miRNA mimics, inhibitors, or expression vectors, there are several ongoing clinical trials in oncology, e.g. with miR-34a mimics (Adams et al. 2015) or miR-16 mimics (Kao et al. 2015, Quinn et al. 2015).

MiRNAs are endogenous small non-coding RNAs. They attenuate mRNA translation posttranscriptionally by binding to the 3 '-untranslated region of mRNA. The matching is guided by specific "seed" sequence of 6-8 nucleotides of a miRNA and results in the inhibition of translation, destabilization and subsequent degradation of target mRNA (Krol et al. 2012). One miRNA can regulate many genes which could be functionally different, or linked in a specific intracellular pathway. While miRNAs are supposed to regulate more than $50 \%$ of human genes, their network interferes with most cellular processes like metabolic and energetic maintenance, differentiation, cell cycle and proliferation, survival, or death (Esquela-Kerscher et al. 2006). Therefore, dysregulation of miRNAs' expression is linked with various pathological states, including solid tumors (Ruan et al. 2009). Quantity of in vitro and in vivo evidences indicate, that change in pathological miRNAs levels is capable of transforming the cancer cell phenotype.

Significant changes in miRNA expression could be found in tumors compared with relevant healthy tissue. By large-scale miRNA profiling and following validation, our group has previously identified miRNAs significantly altered in CRC. Among others, miR-215 was identified as decreased, and in vitro functionally characterized as tumor suppressor (Faltejsková et al. 2012). It was also found down-regulated in patients with
CRC relapse (Karaayvaz et al. 2011). MiR-215 influences apoptosis, cell cycle, viability, and migration of CRC cells in vitro (Faltejsková et al. 2012). It is tightly associated with protein p53, since p53 is induced by miR-215, and miR-215 is regulated by $\mathrm{p} 53$ in a feedback loop. By induction of p21, miR-215 is able to stop cell cycle, and it also inhibits expression of thymidylate synthase, dihydrofolate reductase (Braun et al. 2008) and BMII gene, that plays a role in cancer cells self-renewal ability (Jones et al. 2015). Transcription of miR-215 is activated by transcription factor CDX1 (caudal-type homeobox 1), which regulates differentiation of enterocytes and is frequently downregulated due to hypermethylation of promotor in CRC (Jones et al. 2015). Down-regulation of this miRNA is suggested to be one of the early steps in colorectal neoplastic transformation, as tumors initiated both by $A P C$ gene mutations, and chronic inflammation share this specific molecular pathology (Necela et al. 2011). Moreover, our group has recently found, that overexpression of miR-215 in colorectal cancer cell line leads to significant decrease in tumor volume in tumorigenicity assay in vivo (Vychytilová-Faltejsková data not yet published).

Altogether, these findings suggest possible therapeutic roles of miR-215 in CRC. Therefore, the aim of this work was to study the possibility of increasing the intracellular level of miR-215 in tumor by systemic administration of miRNA mimics in liposomal delivery system in vivo.

\section{Methods}

\section{Subcutaneous xenotransplantation}

All animal procedures were performed in accordance with the Czech legislation (Act No. 246/1992) and with approval of both local and national Committees for Animal Welfare. NSG mice (18-27 g, 8-14 weeks old) were housed and monitored in an individually ventilated cage system (Techniplast, Buguggiate, Italy) with ad libitum access to water and feeding. The subcutaneous xenotransplantation of human cancer cells was performed according to the protocol described by Morton and Houghton (2007) with minor changes. Briefly, mice were anesthetized with etomidate $\left(30 \mathrm{mg} / \mathrm{kg}\right.$ ) by i.p. injection. $2.5 \times 10^{6}$ human CRC cells HCT-116 ${ }^{+/+}$suspended in $100 \mu 1$ of phosphate-buffered saline (PBS) were injected subcutaneously on dorsal site of a mouse. On Day 7 postinoculation, palpable tumor 
with approximate volume of $500 \mathrm{~mm}^{3}$ were present in each animal (Fig. 1).

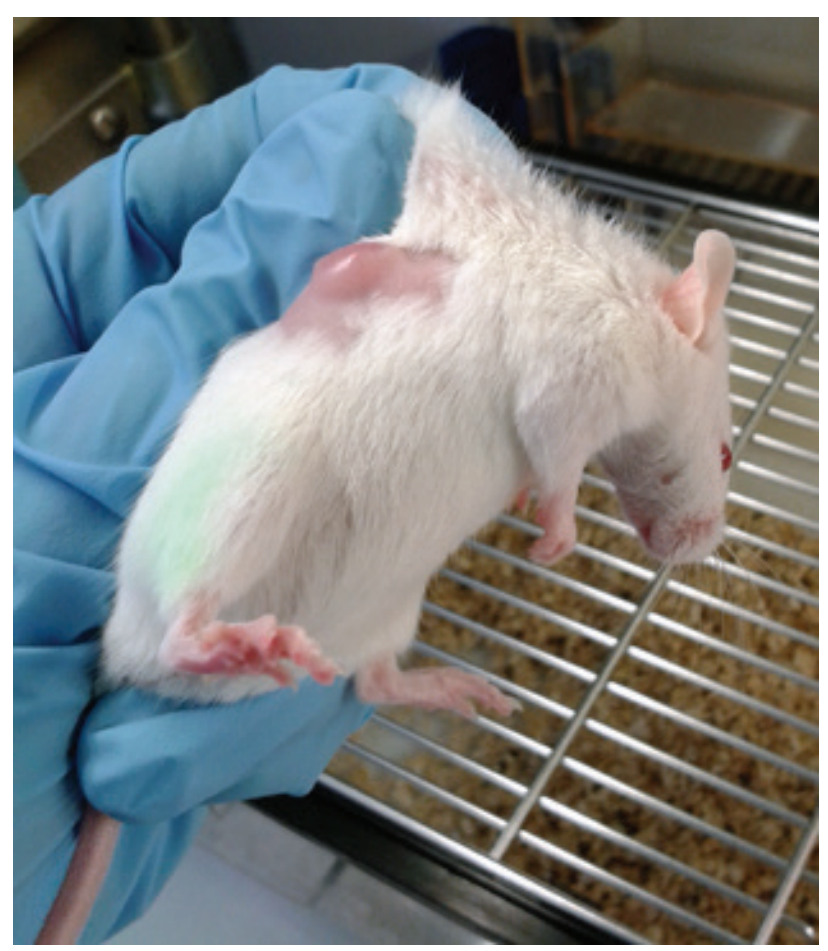

Fig. 1. Mouse with subcutaneous tumor seventh day postinoculation.

Preparation of miRNA mimics encapsulated in liposomes MaxSuppressor ${ }^{\mathrm{TM}}$ In Vivo RNA-LANCEr II (Bioo Scientific, Austin, USA) was used as a liposomal delivery system. MiRNA mimics (mirVana ${ }^{\mathrm{TM}}$ miRNA mimic hsa-miR-215, Thermo Fischer Scientific, Waltham, USA) and negative control oligonucleotide (mirVana ${ }^{\mathrm{TM}}$ miRNA mimic Negative Control \#1, Thermo Fischer Scientific, Waltham, USA) were encapsulated into the liposomes according to the manufacturer's protocol. Briefly, RNA substances were diluted in water for injections (B.Braun Medical, Hessen, Germany) to $10 \mathrm{mg} / \mathrm{ml}$ and stored in $-80^{\circ} \mathrm{C} .11 \mu \mathrm{l}$ of RNA solution [10 $\mu \mathrm{l}(0.1 \mathrm{mg})+10 \%$ excess], $55 \mu \mathrm{l}$ of PBS $10 \times$ and $434 \mu \mathrm{l}$ RNase-free water were added into 1 bottle of MaxSupressor ${ }^{\mathrm{TM}}$ which consists of $50 \mu \mathrm{l}$ of neutral lipid emulsion (NLE). The mixture was sonicated for $5 \mathrm{~min}$ in room temperature.

\section{Experimental treatment}

Two doses [20 $\mu \mathrm{g}(1 \mathrm{nmol}) / \mathrm{mouse}$, and $40 \mu \mathrm{g}$ ( $2 \mathrm{nmol}) /$ mouse] of miRNA mimics encapsulated in liposomes were tested in animal model of CRC, which was established by subcutaneous xenotransplantation. For the dose of $20 \mu \mathrm{g} /$ mouse, 1 bottle of MaxSupressor ${ }^{\mathrm{TM}}$ mixture was dived into 5 doses of $100 \mu \mathrm{l}$ volume, and 2.5 doses in the case of higher dosing, while the volume of injection was increased to $200 \mu$ l. Intravenous injection into the tail vein started on Day 7 postinoculation.

In the Experiment A, $12 \mathrm{NSG}$ mice were randomly divided into 3 groups: a) active treatment (miRNA mimics in liposomes, $20 \mu \mathrm{g} /$ mouse), b) negative control (negative control oligonucleotide in liposomes), and c) saline. Tail-vein injections were repeated after $48 \mathrm{~h}$ for total 4 times. $24 \mathrm{~h}$ after the last dose, mice were sacrificed by anesthetic overdosing.

In the Experiment B, 12 NSG mice were randomly divided into 3 groups: a) active treatment (40 $\mu \mathrm{g} /$ mouse), b) negative control, and c) saline. Following procedures were the same as in Experiment A.

In the Experiment $\mathrm{C}, 10 \mathrm{NSG}$ mice were randomly divided into 2 groups: a) active treatment (20 $\mu \mathrm{g} /$ mouse), b) control (saline). Tail-vein injections were repeated after $48 \mathrm{~h}$ for total 3 times. $24 \mathrm{~h}$ after the last dose, mice were sacrificed.

At the end of all experiments, a necropsy was performed, tumors were extirpated, and measured by Vernier caliper. Lungs and liver were removed and washed with sterile saline. All tissues were stored in RNAlater (Sigma-Aldrich, Waltham, USA) for further analysis.

\section{Determination of miR-215 expression in animal tissues}

Tissue specimens were homogenized (MM301, Retsch GmbH \& Co. KG, Germany) and total RNA was isolated using mirVana miRNA Isolation Kit (Ambion, Austin, USA) according to the manufacturer's protocol. Concentration and purity of the isolated RNA were determined spectrophotometrically using Nanodrop ND-1000 (Thermo Fisher Scientific, Waltham, USA). Reverse transcription was performed using gene-specific primer (hsa-miR-215-5p) according to the TaqMan MicroRNA Assay protocol. TaqMan Universal PCR Master Mix (NoUmpErase UNG; Thermo Fisher Scientific, Waltham, USA) was used for RT-PCR quantification, which was performed on QuantStudio 12K Flex Real-time PCR System (Applied Biosystems, Foster City, USA).

\section{Data normalization and statistical analysis}

Tumor volume was calculated using a mathematical approximation $\mathrm{V}=0.5 \times(\mathrm{L} \times \mathrm{W})^{2}$, where $\mathrm{L}$ and $\mathrm{W}$ stand for length and width of a tumor, 
respectively. Tumor volumes were analyzed using Kruskal-Wallis test in the case of three groups of treatment, or Mann-Whitney test when comparing two groups (both GraphPad Prism 5.03). Normalized (2-(Ct-40) miR-215 expression data were analyzed by KruskalWallis test or Mann-Whitney test, respectively (GraphPad Prism 5.03). $p$-values $\leq 0.05$ were considered statistically significant.

\section{Results}

Effect of intravenous administration of miR-215 mimic on tumor volume

Experiments $\mathrm{A}$ and $\mathrm{B}$ assessed the effect of intravenous administration of miR-215 mimics on tumor growth in mice model of CRC. The model was established by subcutaneous xenotransplantation of human CRC cells HCT-116 ${ }^{+/+}$. Tail-vein injections started on Day 7 postinoculation and were repeated 4 times. In Experiment A, miRNA mimics were administered in the dose of $20 \mu \mathrm{g} /$ mouse and were encapsulated in liposomes.

Interestingly, there were no statistically significant changes in tumor volume measured after 4 administrations of $20 \mu \mathrm{g}$ miR-215 mimics compared with negative control (negative control oligonucleotide in liposomes), or saline (Kruskal-Wallis test, $p>0.05$, Fig. 2A). Expression of miR-215 in tumor tissue was quantified by RT-PCR. In accordance with the results related to the tumor volume, miR-215 level was not significantly higher in the group of mice treated with miR-215 mimics compared with the negative control and saline (Kruskal-Wallis test, $p>0.05$ ), however a slight trend in increase could be seen here (Fig. 2B).
As the results of Experiment A were negative, we stated two hypotheses of responsible issues. The first was potentially inappropriate dose. To test this, we increase the dose of miR-215 to $40 \mu \mathrm{g} /$ mouse. The design of Experiment B was the same. Again, there were no significant changes in tumor volume measured after 4 administrations of miR-215 mimics compared with negative control and saline (Kruskal-Wallis test, $p>0.05$, Fig. 3A). We have also measured the level of miR-215 in tumor tissue by qRT-PCR and the results were quite similar as in Experiment A, i.e. non-significant trend in increase of miR-215 in tumors of animal treated with miRNA mimics (Kruskal-Wallis test, $p>0.05$, Fig. 3B).

The second hypothesis was related to extratumoral accumulation of liposomes. In order to verify this, we removed lungs and liver from 1 animal per group from Experiment $B$ and analyzed the levels of miR-215. In these pilot settings, we obtain interesting comparison suggesting potential accumulation in lungs, although this result was quite preliminary because of minimal number of samples (data not shown).

Potential extratumoral accumulation with liposomes containing miRNA mimics cargo

Experiment $\mathrm{C}$ was intended to elucidate the potential undesired accumulation of the liposomal delivery system. Number of treatment groups was reduced to the active treatment by liposomal miR-215 mimics (20 $\mu \mathrm{g} / \mathrm{mouse})$, and saline. Tumors, lungs and liver were gathered from all animals $(N=10)$. As was expected, there were no statistically significant changes in tumor volume measured after 3 administrations of miR-215 mimics compared with saline (Mann-Whitney test, $p>0.05$, Fig. 4A). An increase in the levels of
(A)

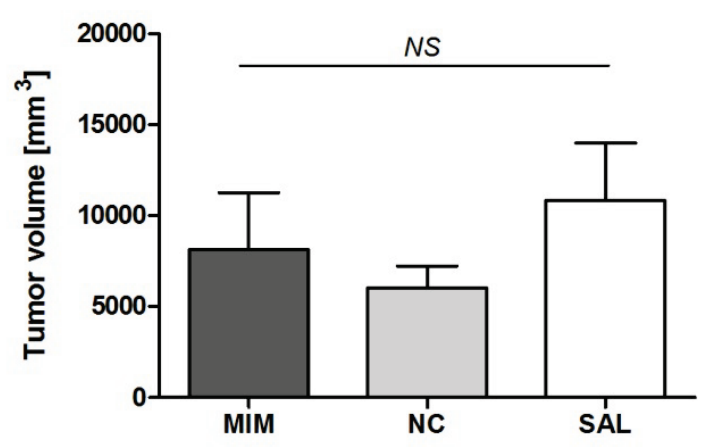

(B)

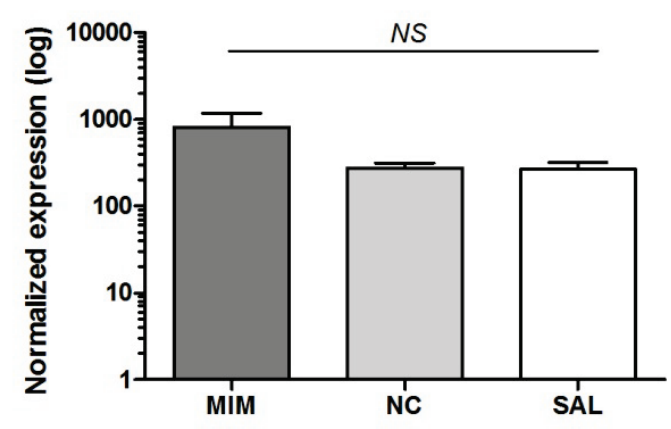

Fig. 2. Tumor volume (A) and miR-215 expression (B) in Experiment $A$ after four administrations of miR-215 mimics (20 $\mu \mathrm{g} / \mathrm{mouse}$, $\mathrm{MIM})$, negative control oligonucleotide (NC), or saline (SAL). Each group consisted of 4 mice. Kruskal-Wallis test, NS not significant $(p>0.05)$. 
(A)

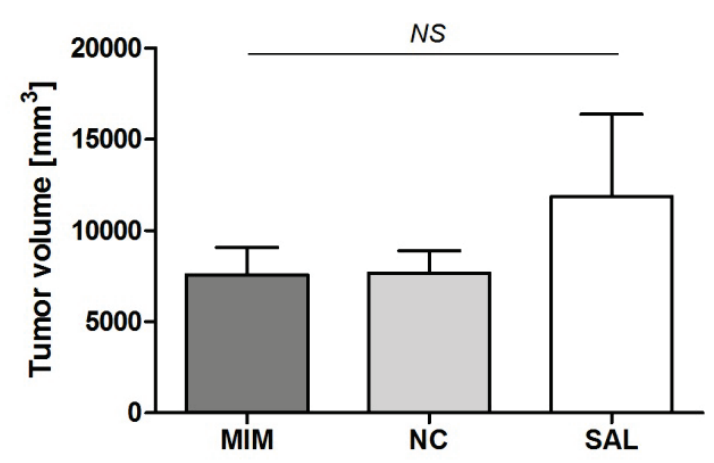

(B)

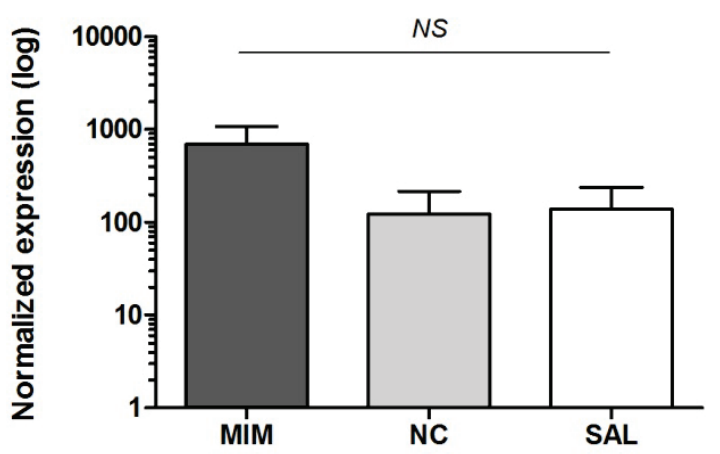

Fig. 3. Tumor volume (A) and miR-215 expression (B) in experiment $B$ after four administrations of miR-215 mimics (40 $\mu g / m o u s e$, MIM), negative control oligonucleotide (NC), or saline (SAL). Each group consisted of 4 mice. Kruskal-Wallis test, NS not significant $(p>0.05)$.

(A)

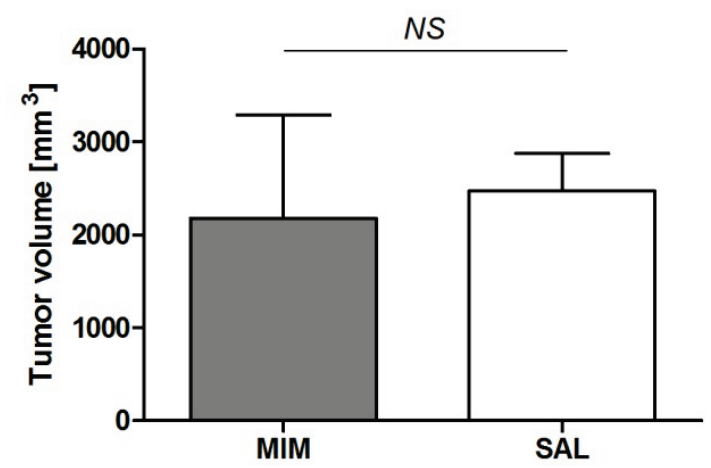

(B)

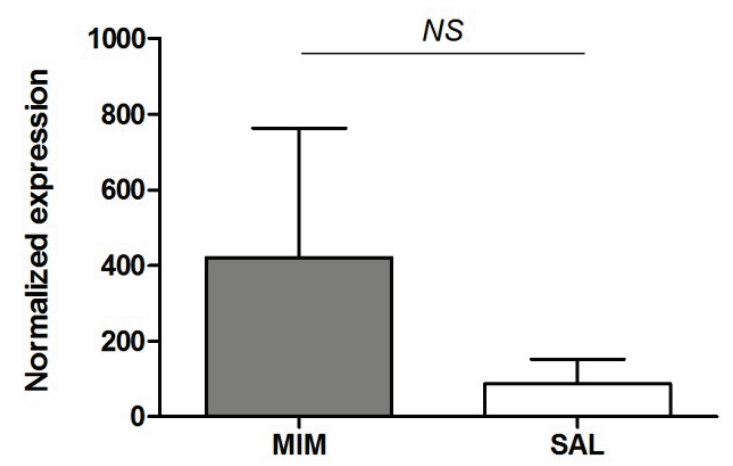

Fig. 4. Tumor volume $(\mathbf{A})$ and miR-215 expression (B) in experiment $C$ after three administrations of miR-215 mimics (20 $\mu \mathrm{g} / \mathrm{mouse}$ MIM), or saline (SAL). Each group consisted of 5 mice. Mann-Whitney test, NS not significant $(p>0.05)$.

miR-215 in tumors of mimics-treated mice was not statistically significant probably due to higher variability of measured levels (Mann-Whitney test, $p>0.05$, Fig. 4B).

We have observed low expression of miR-215 in lungs and tumors of control animals treated with saline. MiR-215 levels was significantly higher in lungs of mimics-treated animals than in tumors of the same animals, and also than in tumors and lungs of control saline-treated mice (Kruskal-Wallis test, $p=0.0277$, Fig. 5A). Although the result suffered with high variability of miR-215 lungs expression levels, the hypothesis of lung accumulation seems to be a possible explanation. The expression of miR-215 in liver was high both in active treatment and in control group, and the groups did not significantly differ (Mann-Whitney test, $p>0.05$, Fig. 5B). Thus, we can assume no liver accumulation.

\section{Discussion}

MiR-215 was proved as tumor suppressor in
CRC both descriptively in human tumor tissue, and functionally in stable cell lines. As it is down-regulated in tumor, increase of miR-215 levels is associated with decreased proliferation, viability, and migration of cancer cells in vitro, and decreased tumor volume in vivo (Braun et al. 2008, Faltejsková et al. 2012).

The aim of our study was to increase miR-215 intracellular levels by systemic administration of miRNA mimics. These substances are oligonucleotides with various chemical modifications in the structure made in order to grant higher effect than native mature miRNAs through higher affinity to the target mRNA. We have chosen liposomal delivery system, since liposomes have already been a part of standard pharmacotherapy (e.g. liposomal doxorubicin, amphotericin B etc.). Liposomes could be accumulated in tumor site by enhanced permeability and retention effect caused by imperfect neoangiogenesis and delayed lymphangiogenesis (Matsumura and Maeda 1986). The most important benefit of the liposomal reagent MaxSuppressor ${ }^{\mathrm{TM}}$ In 
(A)

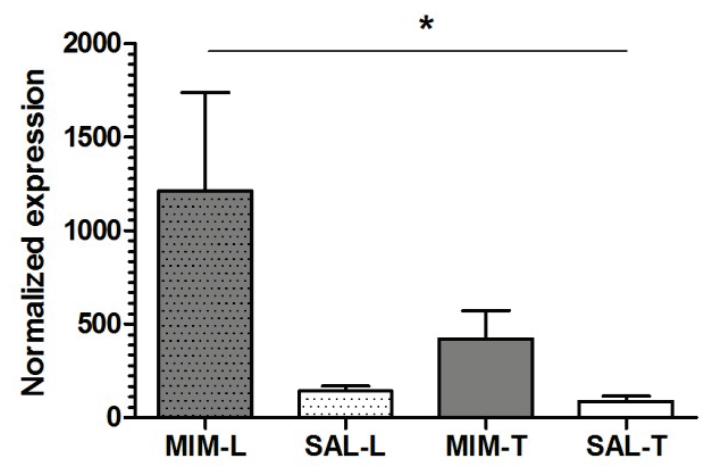

(B)

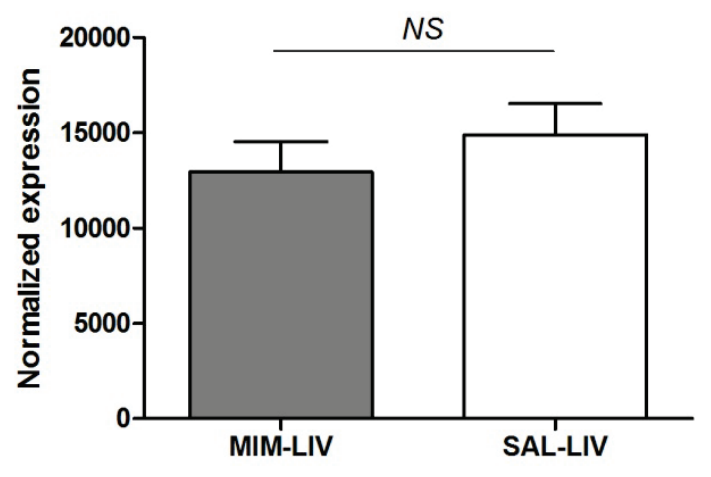

Fig. 5. Comparison of miR-215 expression in lungs and tumor (A) and in the liver (B) in experiment $C$ after three administrations of miR-215 mimics $(20 \mu \mathrm{g} /$ mouse, MIM), or saline (SAL). Each group consisted of 5 mice, L stands for lungs, LIV liver, $\mathrm{T}$ tumors. Kruskal-Wallis test $(\mathbf{A})$, or Mann-Whitney test (B), NS not significant $(p>0.05),{ }^{*} p=0.0277$.

Vivo RNA-LANCEr II is the use of charge neutral lipids (NLE). While cationic lipids have enhanced capacity for binding negatively charged oligonucleotides, they exert electrostatic interactions with various molecules on the cell surface and could decrease proliferation, or alter gene expression (Wu et al. 2001). Liposomes originating from positively charged lipids could also form aggregates with plasma proteins which leads to elimination by mononuclear phagocyte system and accumulation in liver and spleen (Zhang et al. 2012). By choosing charge neutral lipid emulsion, we assumed to avoid these issues and retain positive aspects of liposomal delivery system.

MaxSuppressor ${ }^{\mathrm{TM}}$ In Vivo RNA-LANCEr II has been previously used in animal models of cancer diseases to delivery miRNA-based experimental therapeutics. Most of this experiments used intratumoral delivery of liposomes, but doses similar to ours were also used intravenously in subcutaneous xenografts, orthotopic models and metastasis models of lung, breast, and prostate carcinoma, multiple myeloma, Ewing's sarcoma etc. (Trang et al. 2011, DeVito et al. 2011, Amodio et al. 2012, Imam et al. 2012, DiMartino et al. 2013, Hatano et al. 2015).

Unfortunately, we were not able to significantly increase intracellular levels of miR-215 in tumor by intravenous administration of miR-215 mimics encapsulated in NLE liposomes. Not surprisingly with this finding, the tumor volume also did not differ between the treatment groups. In a search for a possible explanation, we have stated two hypotheses.

The first was related to the appropriate dose. Doses ranging from 20 to $30 \mu \mathrm{g} /$ mouse were frequent in the literature. Although we have assessed two doses, they were not proportionally different because we were limited with the tolerable volume of intravenous injection in mice and from the other side with encapsulation capacity of NLE liposomes guaranteed by the manufacturer. Moreover, a trend in increase of miR-215 in the group of mice treated with $20 \mu \mathrm{g}$ miR-215 mimics, which was not statistically significant, was later repeated but not augmented after administration of $40 \mu \mathrm{g}$ mimics/mouse assuming no dose-dependent observable changes. The dose remains an important point that need further research, however we have focused on the second hypothesis - a possibility of extratumoral accumulation.

Almost all new delivery systems have to deal with plasma protein interactions and possible recognition by circulating or organ immune cells followed by elimination. Trang et al. (2011) described the situation $10 \mathrm{~min}$ after intravenous injection of $20 \mu \mathrm{g}$ of miR-214 mimics in NLE liposomes. They found highest level in blood (approx. 4 mil. copies/10 ng RNA), while in perfused lung, there were approx. 34,000 copies/10 ng RNA, and in the liver approx. 4,000/10 ng RNA. They also assessed distribution of NLE liposomes with oligonucleotide cargo into orthotopic lung tumors by in vivo bioimaging $48 \mathrm{~h}$ after administration and successfully used miR-34 and let-7b mimics in NLE formulation in orthotopic animal model of lung carcinoma (Trang et al. 2011). Together with our findings, it could be concluded, that lung accumulation probably prevails over time in NLE liposomes, which makes them suitable for distribution of drugs or experimental substances into the lung tissue.

Our study is limited primarily with variability of some of the measurements originating probably from small number (4-5) of mice in the treatment groups, which influences statistical significance of some of the 
results. Another limitation lies in the use of subcutaneous model. As this setting is relatively easy to produce, monitor and maintain, and it is generally the most frequently used approach, it has quite limited translational potential. Our results cannot be applied for an estimation of intestinal or colonic distribution of liposomal dosage form. Orthotopic model of CRC, created by implantation of human cancer cells into the intestinal wall of caecum in mice under general anesthesia would produce more complex picture.

\section{Conclusions}

The application of NLE liposomes in animal model of CRC likely requires substantial optimization mainly in terms of the model type, route of administration and posology. It could not also be excluded that it represents an impass. Nevertheless, miR-215 remains an auspicious therapeutic target in CRC for its tumor suppressor effects, even though there are still some obstacles to deal with in order to bring this miRNA closer to clinical practice.

\section{Conflict of Interest}

There is no conflict of interest.

\section{Acknowledgements}

The authors thank Jan Verner for his advice and everyday care for the animals, and Jaroslav Nádeníček and Kamila Součková for technical assistance in the Animal Facility. This work was supported by Faculty of Medicine internal projects MUNI/11/InGA09/2014, MUNI/A/1116/2014 and MUNI/A/1284/2015, and by the project GA16$18257 \mathrm{~S}$ of The Grant Agency of Czech Republic.

\section{References}

ADAMS BD, PARSONS C, SLACK FJ: The tumor-suppressive and potential therapeutic functions of miR-34a in epithelial carcinomas. Expert Opin Ther Targets 20: 737-753.

ADELSTEIN BA, DOBBINS TA, HARRIS CA, MARSCHNER IC, WARD RL: A systematic review and metaanalysis of KRAS status as the determinant of response to anti-EGFR antibodies and the impact of partner chemotherapy in metastatic colorectal cancer. Eur J Cancer 47: 1343-1354, 2011.

AMODIO N, LEOTTA M, BELLIZZI D, DI MARTINO M, D'AQUILA P, LIONETTI M, FABIANI F, LEONE E, GULLÀ A, PASSARINO G, CARAGLIA M, NEGRINI M, NERI A, GIORDANO A, TAGLIAFERRI P, TASSONE P: DNA-demethylating and anti-tumor activity of synthetic miR-29b mimics in multiple myeloma. Oncotarget 3: 1246-1258, 2012.

BRAUN CJ, ZHANG X, SAVELYEVA I, WOLFF S, MOLL UM, SCHEPELER T, ØRNTOFT TF, ANDERSEN CL, DOBBELSTEIN M: p53-responsive microRNAs 192 and 215 are capable of inducing cell cycle arrest. Cancer Res 24: 10094-10104, 2008.

DE VITO C, RIGGI N, SUVÀ ML, JANISZEWSKA M, HORLBECK J, BAUMER K, PROVERO P, STAMENKOVIC I: Let-7a is a direct EWS-FLI-1 target implicated in ewing's sarcoma development. PLoS ONE 6: e23592, 2011.

Di MARTINO MT, GULLÀ A, CANTAFIO ME, LIONETTI M, LEONE E, AMODIO N, GUZZI PH, FORESTA U, CONFORTI F, CANNATARO M, NERI A, GIORDANO A, TAGLIAFERRI P, TASSONE P: In vitro and in vivo anti-tumor activity of miR-221/222 inhibitors in multiple myeloma. Oncotarget 4: 242-255, 2013.

DUŠEK L, MUŽÍK J, KUBÁSEK M, KOPTÍKOVÁ J, ŽALOUDÍK J, VYZULA R: Epidemiologie zhoubných nádorů v České republice [online]. Masarykova univerzita [cit. 2016-7-22]. Dostupný z WWW: http://www.svod.cz. Verze 7.0, 2007, ISSN 1802-8861.

ESQUELA-KERSCHER A, SLACK FJ: Oncomirs-microRNAs with a role in cancer. Nat Rev Cancer 6: 259-269, 2006.

FALTEJSKOVÁ P, SVOBODA M, ŠRUTOVÁ K, MLČOCHOVÁ J, BEŠŠE A, NEKVINDOVÁ J, RADOVÁ L, FABIAN P, SLABÁ K, KISS I, VYZULA R, SLABÝ O: Identification and functional screening of microRNAs highly deregulated in colorectal cancer. J Cell Mol Med 16: 2655-2666, 2012.

FERLAY J, SOERJOMATARAM I, ERVIK M, DIKSHIT R, ESER S, MATHERS C, REBELO M, PARKIN DM, FORMAN D, BRAY F: GLOBOCAN 2012 v1.0, Cancer incidence and mortality worldwide: IARC CancerBase No. 11 [online]. International Agency for Research on Cancer [cit. 2016-7-22]. Dostupný z WWW: http://globocan.iarc.fr. 2013. 
FÍNEK J, HOCH J, KALA Z, KISS I, KOCÁKOVÁ I, KOLÁŘOVÁ I, OBERMANNOVÁ R, PETRUŽELKA L, PRAUSOVÁ J, RYSKA M, SOUMAROVÁ R, TOMÁŠEK J, VÁLEK V, VYZULA R, ZAVORAL M: Zhoubný novotvar kolorekta (C18-20). In: Modrá Kniha České Onkologické Společnosti. VYZULA R. (ed.), Masarykův Onkologický Ústav, Brno, 2016, pp 27-38.

HATANO K, KUMAR B, ZHANG Y, COULTER JB, HEDAYATI M, MEARS B, NI X, KUDROLLI TA, CHOWDHURY WH, RODRIGUEZ R, DEWEESE TL, LUPOLD SE: A functional screen identifies miRNAs that inhibit DNA repair and sensitize prostate cancer cells to ionizing radiation. Nucl Acids Res 43: 4075-4086, 2015.

IMAM JS, PLYLER JR, BANSAL H, PRAJAPATI S, BANSAL S, REBELES J, CHEN HH, CHANG YF, PANNEERDOSS S, ZOGHI B, BUDDAVARAPU KC, BROADDUS R, HORNSBY P, TOMLINSON G, DOME J, VADLAMUDI RK, PERTSEMLIDIS A, CHEN Y, RAO MK: Genomic loss of tumor suppressor miRNA-204 promotes cancer cell migration and invasion by activating AKT/mTOR/Rac1 signaling and actin reorganization. PLoS ONE 7: e52397, 2012.

JONES MF, HARA T, FRANCIS P, LI XL, BILKE S, ZHU Y, PINEDA M, SUBRAMANIAN M, BODMER WF, LAL A: The CDX1-microRNA-215 axis regulates colorectal cancer stem cell differentiation. Proc Natl Acad Sci U S A 112: E1550-E1558, 2015.

KAO SC, FULHAM M, WONG K, COOPER W, BRAHMBHATT H, MACDIARMID J, PATTISON S, SAGONG JO, HUYNH Y, LESLIE F, PAVLAKIS N, CLARKE S, BOYER M, REID G, VAN ZANDWIJK N: A significant metabolic and radiological response after a novel targeted microRNA-based treatment approach in malignant pleural mesothelioma. Am J Respir Crit Care Med 191: 1467-1469, 2015.

KARAAYVAZ M, PAL T, SONG B, ZHANG C, GEORGAKOPOULOS P, MEHMOOD S, BURKE S, SHROYER K, JU J: Prognostic significance of miR-215 in colon cancer. Clin Colorectal Cancer 10: 340-347, 2011.

KROL J, LOEDIGE I, FILIPOWICZ W: The widespread regulation of microRNA biogenesis, function and decay. Nat Rev Genet 11: 597-610, 2010.

LIN AY, BUCKLEY NS, LU AT, KOUZMINOVA NB, SALPETER SR: Effect of KRAS mutational status in advanced colorectal cancer on the outcomes of anti-epidermal growth factor receptor monoclonal antibody therapy: a systematic review and meta-analysis. Clin Colorectal Cancer 10: 63-69, 2011.

MATSUMURA Y, MAEDA H: A new concept for macromolecular therapeutics in cancer chemotherapy: mechanism of tumoritropic accumulation of proteins and the antitumor agent smancs. Cancer Res 46: 6387-6392, 1986.

MORTON CL, HOUGHTON PJ: Establishment of human tumor xenografts in immunodeficient mice. Nature Protoc 2: 247-250, 2007.

NECELA BM, CARR JM, ASMANN YW, THOMPSON EA: Differential expression of microRNAs in tumors from chronically inflamed or genetic (APC(Min/+)) models of colon cancer. PloS ONE 6:e18501, 2011.

QUINN L, FINN SP, CUFFE S, GRAY SG: Non-coding RNA repertoires in malignant pleural mesothelioma. Lung Cancer 90: 417-426, 2015.

RUAN K, FANG X, OUYANG G: MicroRNAs: novel regulators in the hallmarks of human cancer. Cancer Lett 285: 116-126, 2009.

TRANG P, WIGGINS JF, DAIGE CL, CHO C, OMOTOLA M, BROWN D, WEIDHAAS JB, BADER AG, SLACK FJ: Systemic delivery of tumor suppressor microRNA mimics using a neutral lipid emulsion inhibits lung tumors in mice. Mol Ther 19: 1116-1122, 2011.

VAN CUTSEM E, CERVANTES A, ADAM R, SOBRERO A, VAN KRIEKEN JH, ADERKA D, ARANDA AGUILAR E, BARDELLI A, BENSON A, BODOKY G, ET AL:: ESMO consensus guidelines for the management of patients with metastatic colorectal cancer. Ann Oncol 27: 1386-1422, 2016.

WU J, LIZARZABURU ME, KURTH MJ, LIU L, WEGE H, ZERN MA, NANTZ MH: Cationic lipid polymerization as a novel approach for constructing new DNA delivery agents. Bioconjug Chem 12: 251-257, 2001.

ZHANG XX, MCINTOSH TJ, GRINSTAFF MW: Functional lipids and lipoplexes for improved gene delivery. Biochimie 94: 42-58, 2012. 